In his last letter, Sir Henry Howorth expresses his belief that, as a consequence of the recent correspondence, I have been led to change the opinions I previously held as to the cause of an Ice Age. May I assure Sir Henry Howorth that he must have quite mistaken the purport of my letter.

With all due courtesy to Sir Henry Howorth, as well as to any others who may have differed from me, I may say that I have seen no reason to swerve from the belief that the position taken in my book on "The Cause of an Ice Age" is the sound position. My opinions are, therefore, unchanged.

I would like to take this opportunity to thank Dr. A. R. Wallace for his letter on this subject in your columns, and to express the satisfaction with which I found that he had been led to the same conclusion, with respect to Mr. Culverwell's argument, as that at which $I$ had myself arrived by an independent method. I note that $\mathrm{Mr}$. Culverwell dissents; but, even at the risk of being thought very obstinate, I must say that I still believe Dr. Wallace and $\mathbf{I}$ are right. ROBERT S. BALL.

So far as I know, it has not been suggested that a comparatively small elevation of the crust of the earth would cause a glacial state in the elevated part. The roughness of an ordinary terrestrial globe, representing an elevation that might be compared with the thickness of letter-paper, would correspond with an elevation of the crust of the earth that even in the tropic would cause perpetual snow. A few thousand years would be sufficient to cause a sufficient elevation without any catastrophic hypothesis.

THEODORE RYLAND.

\section{The Measurement of High Temperatures.}

IN a valuable paper on the "Determination of High Tem peratures" (Wied. Ann. 1895, No. 10), Messrs. Holborn and Wien give the results of their observations on the changes in the resistance of platinum wire over a range of $0^{\circ}$ to $1600^{\circ} \mathrm{C}$. The authors come to the conclusion that the relation between temperature and resistance "cannot be accurately represented by the Callendar and Griffiths formula"; although, on the other hand, they admit that by means of that formula Heycock and Neville have determined a number of melting points which are in good agreement ("die sich in guter Uebereinstimmung mit unsern Werthen befinden") with the values found by Holborn and Wien when using a thermo-couple standardised by direct comparison with the air-thermometer.

Platinum thermometers are now so generally used for high temperature measurements that an adverse conclusion of thi kind is a matter of importance, especially when associated with the names of accurate observers such as Holborn and Wien.

I trust, therefore, that a brief criticism will not be regarded as out of place.

I would first remark that my delay in commenting on this paper is not due to any want of respect for the authors, but from a sense of the importance of the matter. Before attempting any reply, I wished to ascertain the views of Prof. Callendar, and I accordingly wrote to Montreal calling his attention to the paper, but I have not as yet received his answer. I feel, however, that further delay is undesirable.

Neither Prof. Callendar nor I have at any time claimed that the relation between $t$ and $p t$, as given by the empirical formula, has been rigorously verified at temperatures exceeding $600^{\circ} \mathrm{C}$.

In NATURE, November I895, p. 40, I wrote as follows:" Results of this kind prove that even if the reduction does not express the temperature accurately in the air-scale, it at all events gives us a constant scale in which all high temperatures can be expressed, and it is further evident that this constant scale differs but little (even at these high temperatures) from the true air-scale."

The context shows that the "high temperatures" referred to were those in the neighbourhood of $1100^{\circ} \mathrm{C}$.

The above quotation defines my own position with sufficient accuracy, and I will therefore pass on to consider the work of Messrs. Holborn and Wien.

(I). The authors state that the platinum wires (in experiments up to $1200^{\circ} \mathrm{C}$.) were placed in an externally glazed porcelain tube, and isolated from each other by means of special porcelain capillaries ("die Drähte wurden durch besondere Porzellan Capillaren von einander isolirt"); and at higher temperatures "in externally glazed tubes of a very infusible substance, and isolated from each other by capillaries of the same material.'
From this description it appears evident that the wire was in contact with the porcelain, or the other material, probably throughout the greater portion of its length; otherwise it must have been subjected to some strain. Now, contact with porcelain or any similar substance has been found by us to be absolutely fatal : if by any chance the wire has come into contact with the walls of the surrounding tube at high temperatures, the coil has had to be replaced by a new one. This is probably caused by the action of the silica; but whatever the reason may be, the effect has long been known, and care has been taken to avoid this source of error.

It is true that in the present form of the platinum thermometer the wire comes into contact with mica, and I have little doubt that some similar action (although in a lesser degree) takes place between the platinum and the mica. The method of constructing the framework and coil, however, causes the length of platinum in actual contact with the mica to be but an exceedingly small fraction of the length of the wire (probably less than $\left.{ }_{1}^{\frac{1}{6}}-\mathrm{th}\right)$, and thus any such effect is diminished. I think it possible that the small changes at high temperatures to which I have called attention in NATURE, (November I895, p. 40), are in some measure due to action at the points of contact.

Unless Holborn and Wien took greater precautions in regard to this matter of contact between case and wire than they indicate in their paper, there is no need to seek for further explanation of the somewhat erratic behaviour of the two platinum wires examined by them; in fact, other experiments by the same observers show how materially the resistance of platinum is affected by exposure to the action of silica or hydrogen.

(2). No adverse conclusion should be drawn from the changes in their Wire No. I., for the authors state that "at the termination of the observations the protecting tube was found to have broken in the oven, and the wire had been exposed to the gases of the oven."

The necessity of complete protection from the furnace gases has from the first been insisted upon by those accustomed to the use of platinum thermometers. It was want of attention to this essential matter which led the B. A. Committee of I874 to a false conclusion. The behaviour of Holborn and Wien's Wire I. has no significance or value, except in so far as it emphasises the importance of complete protection. It appears doubtful if sufficient precautions were taken in this matter with regard to their series of experiments with the platinum Wire II. The infusible tubes which they used for the air-thermometer bulbs at high temperatures were covered externally with a glaze. The authors say: "As the glaze in this case and also in the porcelain becomes liquid much sooner than the softening point of the material, we made use of our method by which there must always be a smaller pressure inside the vessel than outside. Under these conditions the glaze is pressed into the pores of the tubes, otherwise it would immediately come off."

Now I do not find any mention of a similar precaution when heating the platinum wire in what appear to have been similar tubes; it is possible, therefore, that the changes observed in Wire II. were also in some degree due to contamination by furnace gases.

(3). The authors speak of Wire II. as formed from "pure platinum" ("Aus reinem Platin"). They give the value of its temperature coefficient as-

$$
\begin{array}{llllll}
\text { Before heating } & \ldots & \ldots & \ldots & \ldots & { }^{\circ} \mathrm{OO} 38 \mathrm{OI} \\
\text { After }, & \ldots & \ldots & \ldots & \ldots & { }^{\circ} \mathrm{OO} 3783
\end{array}
$$

As a general rule, the purer the platinum the higher its coefficient. The samples used by us (as, for example, in the Kew Observatory thermometers) have coefficients which vary from .003860 to "003880. It would hardly appear, therefore, that the wire used by Holborn and Wien merits the term "pure." The purity is, however, not of great consequence, as (see NATURE, November 1895, p. 40) we have found that although the coefficient depends on the purity, the deduced temperatures are unaffected provided that the coefficient is not reduced by the impurities to lower than about ${ }^{\circ} \mathrm{OO}_{32}$. The fall in the coefficient (above indicated) is, however, of great significance, and in itself is evidence that the wire had become contaminated during the experiments. Assuming (as was doubtless the case) that the wire had been previously annealed, the above change sufficiently establishes inadequate protection of the wire.

I have carefully investigated the numbers in Table II., where the authors give the results of their observations on this second specimen of "pure platinum." I am unable to draw any con-

NO. 1374 , VOL. 53] 